\title{
SIMULASI DAN ANALISIS ALIRAN DAYA PADA SISTEM TENAGA LISTRIK MENGGUNAKAN PERANGKAT LUNAK ELECTRICAL TRANSIENT ANALYSER PROGRAM (ETAP) VERSI 4.0
}

\author{
Rudi Salman $^{1)}$ Mustamam $^{2)}$ Arwadi Sinuraya ${ }^{3)}$
}

\begin{abstract}
Abstrak
Penelitian ini bertujuan untuk mengetahui kinerja (performance) sistem tenaga listrik yaitu aliran daya aktif maupun reaktif serta profil tegangan setiap bus dalam sistem. Simulasi aliran daya dilakukan menggunakan perangkat lunak Electrical Transient Analyser Program (ETAP) versi 4.0. Penelitian ini dilaksanakan di Jurusan Pendidikan Teknik Elektro dengan objek penelitian adalah Sistem Tenaga Listrik di Sumatera Utara dan Aceh, yang memiliki 107 bus dan terdiri dari 1 bus referensi (Swing Bus), 12 bus generator (Voltage Regulator Bus) dan sisanya yaitu 94 bus adalah bus beban (Load Bus). Perhitungan aliran daya menggunakan metode Newton-Raphson.

Hasil penelitian menunjukan bahwa aliran daya aktif terbesar mengalir dari bus Tebing Tinggi ke bus Sei Rotan sebesar 133,04 (31,52\%) MW dan aliran daya reaktif terbesar mengalir dari bus Belawan (Swing/Reference bus) ke bus Sei Rotan sebesar 66,80 (25,7\%) MVAR. Total aliran daya aktif dan reaktif dalam sistem adalah 422,019 MW dan 259,93 MVAR. Sedangkan untuk profil tegangan bus, penurunan tegangan (Voltage drop) tertinggi terjadi pada bus 55 (bus beban Aek Knopan) sebesar 3,035\% (19,393 KV) dari tegangan normal (20 KV) dan sebesar 149,773 KV (0,151\%) untuk sistem $150 \mathrm{KV}$.
\end{abstract}

Kata kunci : Simulasi Aliran Daya, Profil Tegangan, ETAP 4.0, Losses, Newton-Raphson

\section{Pendahuluan}

Analisis aliran daya merupakan analisis yang digunakan untuk mengetahui kondisi sistem dalam keadaan normal, sehingga sangat dibutuhkan dalam perencanaan sistem untuk masa yang akan datang dan merupakan bahan evaluasi terhadap sistem yang ada. (Stevenson,1996; Saadat,1999 dan Cekmas,2004). Analisis ini meliputi penentuan besarnya nilai tegangan (V), daya aktif (P) dan reaktif (Q) dan sudut fasa $(\delta)$ setiap bus dalam sistem. Selanjutnya menurut Saadat (1999), bus dalam sistem tenaga listrik dapat dikelompokkan 3 jenis, yaitu :

\section{Bus referensi (Swing atau Slack bus)}

Bus ini berfungsi untuk mensuplai kekurangan daya aktif $(\mathrm{P})$ dan daya reaktif (Q) dalam sistem. Parameter atau besaran yang di tentukan adalah tegangan (V) dan sudut fasa $(\delta)$. Setiap sistem tenaga listrik hanya terdapat 1 bus referensi, yaitu bus yang didalamnya terdapat pembangkit atau generator yang memiliki kapasitas terbesar di antara pembangkit yang lain didalam sistem.

\section{Bus generator (Voltage Control Bus)}

Bus ini merupakan bus yang tegangannya dapat dikontrol melalui pengaturan daya reaktif agar tegangannnya tetap. Parameter atau besaran yang diketahui adalah daya aktif (P) dan tegangan (V). Bus ini dinamakan PV bus.

\section{Bus Beban (Load bus)}

Bus ini adalah bus yang terhubung dengan beban sistem. Parameter atau besaran yang ditentukan adalah daya aktif (P) dan daya reaktif (Q), maka bus ini di sebut juga PQ bus.

Sebelum analisis aliran daya dilakukan, komponen sistem yang terdiri dari pembangkit (generator), transformator, saluran transmisi dan beban harus di representasikan atau di modelkan melalui diagram satu garis (oneline diagram) dengan menganggap sistem tiga fasa dalam keadaan seimbang. Diagram ini di maksudkan untuk memberikan gambaran secara ringkas suatu sistem tenaga listrik secara keseluruhan, dalam hal ini sistem tenaga listrik di Sumatera Utara. Untuk itu

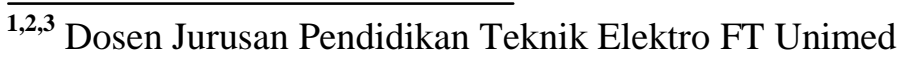


di butuhkan data-data yang terkait dengan komponen-komponen tersebut. Menurut Stevenson (1996), data-data yang dibutuhkan untuk analisis aliran daya adalah sebagai berikut :

a. Data pembangkit (generator), yaitu kapasitas daya aktif (P) dalam satuan Megawatt (MW) dan reaktif (Q) dalam satuan Megavolt Ampere (MVA), tegangan terminal (V) dalam satuan Kilovolt (KV) dan reaktansi sinkron (X) dalam satuan $\operatorname{Ohm}(\Omega)$.

b. Data Transformator Daya, yaitu kapasitas tiap trafo dalam satuan Megavolt Ampere (MVA), tegangan (V) dalam satuan Kilovolt (KV) dan reaktansi bocor (X) dalam satuan $\mathrm{Ohm}(\Omega)$.

c. Data saluran transmisi, yaitu resistansi (R) dalam ohm $(\Omega)$ dan reaktansi (X) dalam ohm $(\Omega)$.

d. Data beban, yaitu daya aktif (P) dalam Megawatt (MW) dan daya reaktif (Q) dalam satuan Megavolt Ampere (MVA).

\section{Matrik Admitansi dan Impedansi Bus}

Untuk menghitung dan menganalisis aliran daya, langkah awal yang dilakukan adalah membentuk matrik admitansi bus sistem tenaga listrik. Gambar 2.1 berikut ini merupakan sebuah contoh sistem tenaga listrik sederhana, dimana impedansinya dinyatakan dalam perunit pada dasar MVA dan resistansi diabaikan untuk penyederhanaan (Saadat,1999).

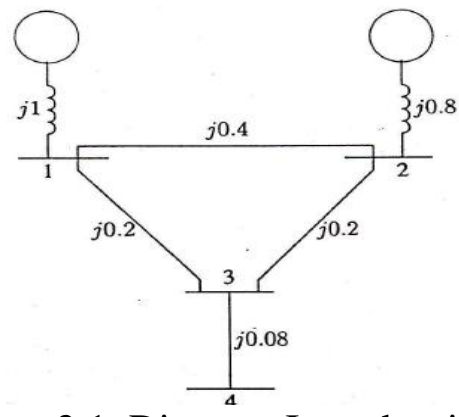

Gambar 2.1. Diagram Impedansi Pada

Sistem Tenaga Listrik Sederhana

Berdasarkan Hukum Arus Kirchoff impedansi-impedansi pada gambar diatas dapat diubah ke bentuk admitansi-admitansi dengan menggunakan persamaan, berikut:

$$
y_{i j}=\frac{1}{Z_{i j}}=\frac{1}{r_{i j}+j x_{i j}}
$$

Selanjutnya gambar 2.1 tersebut di ubah menjadi :

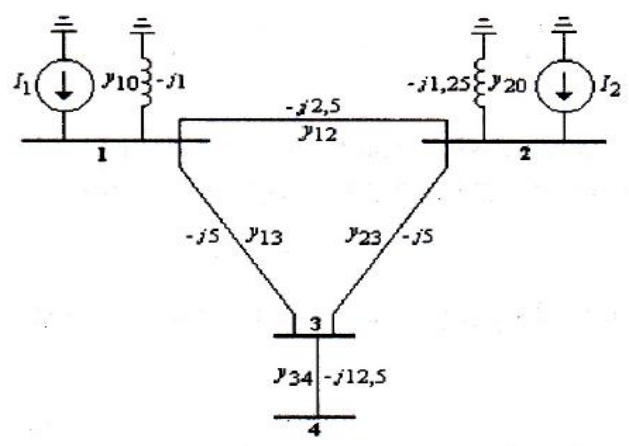

Gambar 2.2. Diagram Admitansi Pada Sistem Tenaga Listrik Sederhana

Dari gambar 2.2 dapat diturunkan persamaan antara simpul-simpul akan menghasilkan persamaan arus :

$$
\begin{aligned}
& I_{1}=y_{10} V_{1}+y_{12}\left(V_{1}-V_{2}\right)+y_{13}\left(V_{1}-V_{3}\right) \\
& I_{2}=y_{20} V_{2}+y_{12}\left(V_{2}-V_{1}\right)+y_{23}\left(V_{2}-V_{3}\right) \\
& 0=y_{23}\left(V_{3}-V_{2}\right)+y_{13}\left(V_{3}-V_{1}\right)+y_{34}\left(V_{3}-V_{4}\right) \\
& 0=y_{34}\left(V_{4}-V_{3}\right)
\end{aligned}
$$

Persamaan tersebut disusun kembali dan akan di peroleh :

$$
\begin{aligned}
& I_{1}=\left(y_{10}+y_{12}+y_{13}\right) V_{1}-y_{12} V_{2}-y_{13} V_{3} \\
& I_{2}=-y_{12} V_{1}+\left(y_{20}+y_{12}+y_{23}\right) V_{2}-y_{23} V_{3} \\
& 0=-y_{13} V_{1}-y_{23} V_{2}+\left(y_{13}+y_{23}+y_{34}\right) V_{3}-y_{34} V_{4} \\
& 0=-y_{34} V_{3}+y_{34} V_{4}
\end{aligned}
$$

dengan :

$$
\begin{aligned}
& Y_{11}=y_{10}+y_{12}+y_{13} \\
& Y_{22}=y_{20}+y_{12}+y_{23} \\
& Y_{33}=y_{13}+y_{23}+y_{34} \\
& Y_{44}=y_{34} \\
& Y_{12}=Y_{21}=-y_{12}
\end{aligned}
$$




$$
\begin{aligned}
& Y_{13}=Y_{31}=-y_{13} \\
& Y_{23}=Y_{32}=-y_{23} \\
& Y_{34}=Y_{43}=-y_{34}
\end{aligned}
$$

Sehingga persamaan arus pada simpul menjadi :

$$
\begin{aligned}
& I_{1}=Y_{11} V_{1}+Y_{12} V_{2}+Y_{13} V_{3}+Y_{14} V_{4} \\
& I_{2}=Y_{12} V_{1}+Y_{22} V_{2}+Y_{23} V_{3}+Y_{24} V_{4} \\
& I_{3}=Y_{31} V_{1}+Y_{32} V_{2}+Y_{33} V_{3}+Y_{34} V_{4} \\
& I_{4}=Y_{41} V_{1}+Y_{42} V_{2}+Y_{43} V_{3}+Y_{44} V_{4}
\end{aligned}
$$

Untuk sistem tenaga listrik dengan jumlah n-bus, persamaan arus simpul dalam bentuk matrik dapat ditulis :

$$
\left[\begin{array}{c}
I_{1} \\
I_{2} \\
\vdots \\
I_{i} \\
\vdots \\
I_{n}
\end{array}\right]=\left[\begin{array}{cccccc}
Y_{11} & Y_{12} & \cdots & Y_{1 i} & \cdots & Y_{1 n} \\
Y_{12} & Y_{22} & \cdots & Y_{2 i} & \cdots & Y_{2 n} \\
\vdots & \vdots & & \vdots & & \vdots \\
Y_{i 1} & Y_{i 2} & & Y_{i i} & & Y_{i n} \\
\vdots & \vdots & & \vdots & & \vdots \\
Y_{n 1} & Y_{n 2} & & Y_{n i} & & Y_{n n}
\end{array}\right]\left[\begin{array}{c}
V_{1} \\
V_{2} \\
\vdots \\
V_{i} \\
\vdots \\
V_{n}
\end{array}\right]
$$

atau

$\boldsymbol{I}_{b u s}=\boldsymbol{Y}_{b u s} \boldsymbol{V}_{b u s}$

dengan $\boldsymbol{I}_{\text {bus }}$ adalah vektor arus bus yang diinjeksikan. Arus positif jika menuju bus dan negatif jika meninggalkan bus. $\boldsymbol{V}_{\text {bus }}$ adalah vektor tegangan bus yang diukur dari simpul referensi. $\boldsymbol{Y}_{\text {bus }}$ adalah matrik admitansi bus. Matrik ini di bentuk dari elemen diagonal masing-masing simpul dan diagonal antara simpul-simpul. Jika arus bus diketahui, persamaan (23) dapat diselesaikan untuk tegangan n-bus, yaitu :

$\boldsymbol{V}_{\text {bus }}=\boldsymbol{Y}_{\text {bus }}^{-1} \boldsymbol{I}_{\text {bus }}$

$\boldsymbol{Y}_{\text {bus }}^{-1}$ adalah invers matrik admitansi bus atau lebih dikenal sebagai matrik impedansi bus $\left(\boldsymbol{Z}_{\text {bus }}\right)$.

\section{Persamaan Aliran Daya}

Jaringan sistem tenaga listrik seperti yang ditunjukkan pada gambar 2.3 saluran transmisinya dapat digambarkan dengan model $\pi$ yang impedansi-impedansinya sudah di ubah menjadi admitansi-admitansi perunit dengan dasar MVA. Penggunaan Hukum Arus Kirchoff pada bus ini diberikan dalam persamaan :

$I_{i}=y_{i 0} V_{i}+y_{i 1}\left(V_{i}-V_{1}\right)+y_{i 2}\left(V_{i}-V_{2}\right)+\ldots+y_{i n}\left(V_{i}-V_{n}\right)$

- $=\left(y_{i 0}+y_{i 1}+y_{i 2}+\ldots+y_{i n}\right) V_{i}-y_{i 1} V_{1}-y_{i 2} V_{2}-\ldots-y_{i n} V_{n 1}$

atau

$$
I_{i}=V_{i} \sum_{j=0}^{n} y_{i j}-\sum_{j=1}^{n} y_{i j} V j \quad j \neq i
$$

Daya aktif dan reaktif pada bus ke- $i$ adalah :

$$
P_{i}+j Q_{i}=V_{i} I_{i}^{*}
$$

atau

$$
I_{i}=\frac{P_{i}-j Q_{i}}{V_{i}{ }^{*}}
$$

Substitusikan persamaan (29) ke persamaan (27), akan diperoleh :

$$
\frac{P_{i}-j Q_{i}}{V_{i}^{*}}=V_{i} \sum_{j=0}^{n} y_{i j}-\sum_{j=1}^{n} y_{i j} V_{j} \quad j \neq i
$$

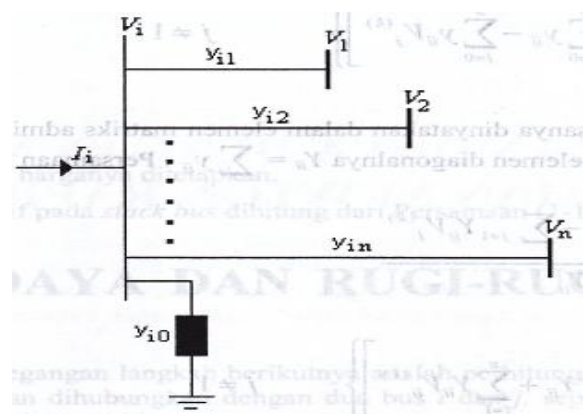

Gambar 2.3. Model bus sistem tenaga listrik sederhana

\section{Metode Newton-Raphson untuk Per- hitungan Aliran Daya}

Pada dasarnya ada 3 metode yang sering digunakan untuk perhitungan aliran daya. Untuk sistem tenaga listrik yang berskala besar metode Newton-Raphson lebih efisien dan praktis, dimana jumlah 
iterasi yang dibutuhkan untuk perhitungan lebih sedikit jika dibandingkan d engan metode yang lainnya. Dalam metode ini persamaan aliran daya dirumuskan dalam bentuk polar. Dari gambar 2.3 dapat ditulis persamaan :

$$
I_{i}=\sum_{j=1}^{n} Y_{i j} V_{j}
$$

Persamaan diatas bila ditulis dalam bentuk Polar akan diperoleh seperti berikut :

$$
I_{i}=\sum_{j=1}^{n}\left|Y_{i j}\right|\left|V_{j}\right| \angle \theta_{i j}+\delta_{j}
$$

berikutnya daya komplek pada bus $i$ dapat ditulis :

$$
P_{i}-j Q_{i}=V_{i}^{*} I_{i}
$$

Dengan mensubstitusikan persamaan (32) ke persamaan (33), akan diperoleh persamaan :

$$
P_{i}-j Q_{i}=\left|V_{i}\right| \angle-\delta_{i} \sum_{j=1}^{n}\left|Y_{i j}\right|\left|V_{i}\right| \angle \theta_{i j}+\delta_{j}
$$

Bagian riil dan imajiner persamaan (34) kemudian dipisahkan didapatkan :

$$
\begin{aligned}
& P_{i}=\sum_{j=1}^{n}\left|V_{i}\right|\left|V_{j}\right|\left|Y_{i j}\right| \cos \left(\theta_{i j}-\delta_{i}+\delta_{j}\right) \\
& Q_{i}=-\sum_{j=1}^{n}\left|V_{i}\right|\left|V_{j}\right|\left|Y_{i j}\right| \sin \left(\theta_{i j}-\delta_{i}+\delta_{j}\right)
\end{aligned}
$$

Persamaan diatas dikembangkan dari deret Taylor seperti persamaan berikut ini :

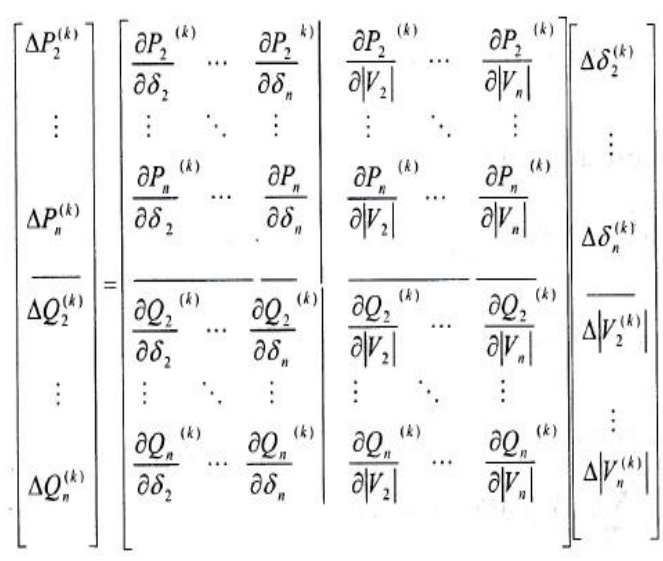

Dalam hal ini dimisalkan bus 1 adalah bus referensi (Swing bus). Maka matrik Jacobian memberikan perbandingan linier antara perubahan pada sudut tegangan $\Delta \delta_{i}^{(k)}$ dan besarnya tegangan $\Delta\left|V_{i}^{(k)}\right|$ dengan sedikit perubahan pada daya aktif $\left(\Delta P_{i}^{(k)}\right)$ dan daya reaktif $\left(\Delta Q_{i}^{(k)}\right)$ dalam bentuk yang mudah atau singkat dapat ditulis :

$$
\left[\begin{array}{l}
\Delta P \\
\Delta Q
\end{array}\right]=\left[\begin{array}{cc}
J_{1} & J_{2} \\
J_{3} & J_{4}
\end{array}\right]\left[\begin{array}{c}
\Delta \delta \\
\Delta|V|
\end{array}\right]
$$

Banyaknya elemen matrik Jacobian persamaan (38) ditentukan dengan (2n-2$2 m) \times(2 n-2-2 m)$ dengan $\mathrm{n}$ adalah banyaknya bus pada sistem dan m adalah banyak bus pembangkit atau generator. $J_{l}$ diperoleh dari $(n-1) \times(n-1), J_{2}$ diperoleh dari $(n-1) \times(n-1-m), J_{3}$ dipeoleh dari $(n-1-$ $m) \mathrm{x}(n-1-m)$ dan $J_{4}$ di peroleh dari $(n-1-m) \mathrm{x}$ $(n-1-m)$.

Sehingga elemen diagonal dan bukan diagonal untuk $J_{l}$ adalah :

$$
\begin{aligned}
& \frac{\partial P_{i}}{\partial \mathcal{S}_{i}}=\sum_{j \neq 1}\left|V_{i}\right|\left|V_{i}\right|\left|Y_{i j}\right| \sin \left(\theta_{i j}-\delta_{i}+\delta_{i}\right) \\
& \frac{\partial P_{i}}{\partial \delta_{j}}=-\left|V_{i}\right|\left|V_{j}\right|\left|Y_{i j}\right| \sin \left(\theta_{i j}-\delta_{i}+\delta_{j}\right) \quad j \neq 1
\end{aligned}
$$

Elemen diagonal dan bukan diagonal untuk $J_{2}$ adalah : 


$$
\begin{aligned}
& \frac{\partial P_{i}}{\partial\left|V_{i}\right|}=2\left|V_{i}\right|\left|Y_{i i}\right| \cos \theta_{i i}+\sum_{j \neq i}\left|V_{j}\right|\left|Y_{i j}\right| \cos \left(\theta_{i j}-\delta_{i}+\delta_{j}\right) \\
& \frac{\partial P_{i}}{\partial\left|V_{j}\right|}=\left|V_{i}\right|\left|Y_{i j}\right| \cos \left(\theta_{i j}-\delta_{i}+\delta_{j}\right) \quad j \neq 1
\end{aligned}
$$

Elemen diagonal dan bukan diagonal untuk $J_{3}$ adalah :

$$
\begin{aligned}
& \frac{\partial Q_{i}}{\partial \delta_{i}}=\sum_{j \neq 1}\left|V_{i}\right|\left|V_{j}\right|\left|Y_{i j}\right| \cos \left(\theta_{i j}-\delta_{i}+\delta_{j}\right) \\
& \frac{\partial Q_{i}}{\partial \delta_{j}}=-\left|V_{i}\right|\left|V_{j}\right|\left|Y_{i j}\right| \cos \left(\theta_{i j}-\delta_{i}+\delta_{j}\right) \quad j \neq 1
\end{aligned}
$$

Elemen diagonal dan bukan diagonal untuk $J_{4}$ adalah :

$$
\begin{aligned}
& \frac{\partial Q_{i}}{\partial\left|V_{i}\right|}=-2\left|V_{i}\right|\left|Y_{i i}\right| \sin \theta_{i i}+\sum_{j \neq i}\left|V_{i}\right|\left|Y_{i j}\right| \sin \left(\theta_{i j}-\delta_{i}+\delta_{j}\right) \\
& \frac{\partial Q_{i}}{\partial\left|V_{j}\right|}=-\left|V_{i}\right|\left|Y_{i j}\right| \sin \left(\theta_{i j}-\delta_{i}+\delta_{j}\right) \quad j \neq 1
\end{aligned}
$$

Harga dari $\Delta P_{i}^{(k)}$ dan $\Delta Q_{i}^{(k)}$ berbeda antara yang terjadwal dengan nilai perhitungan dan ini disebut sisa daya yang diberikan dengan :

$$
\begin{aligned}
& \Delta P_{i}^{(k)}=P_{i}^{s c h}-P_{i}^{(k)} \\
& \Delta Q_{i}^{(k)}=Q_{i}^{s c h}-Q_{i}^{(k)}
\end{aligned}
$$

Perhitungan untuk sudut fasa dan tegangan bus yang baru adalah :

$$
\begin{aligned}
& \delta_{i}^{(k+1)}=\delta_{i}^{(k)}+\Delta \delta_{i}^{(k)} \ldots \ldots \ldots \ldots . . . . . . \\
& \left|V_{i}{ }^{(k+1)}\right|=\left|V_{i}^{(k)}\right|+\Delta\left|V_{i}^{(k)}\right|
\end{aligned}
$$

Langkah-langkah perhitungan aliran daya dengan metode Newton-Raphson adalah sebagai berikut :
1. Pada bus berbeda dimana $P_{i}^{s c h}$ dan $Q_{i}^{s c h}$ harganya ditentukan. Besarnya tegangan dan sudut fasa disamakan dengan nilai bus referensi yaitu 1,0 dan 0,0 , sehingga $\left|V_{i}^{(0)}\right|=1,0$ dan $\delta_{i}^{(0)}=0,0$. Untuk bus pembangkit dimana $V_{i}$ dan $P_{i}^{s c h}$ diatur, sedangkan sudut fasa disamakan dengan sudut bus referensi, maka $\delta_{i}^{(0)}=0$.

2. Hitung $P_{i}^{(k)}$ dan $Q_{i}^{(k)}$ pada bus beban menggunakan persamaan $(35)(36), \Delta P_{i}^{(k)}$ dan $\Delta Q_{i}^{(k)}$ dihitung dengan persamaan (49)(50).

3. Hitung $P_{i}^{(k)}$ dan $\Delta P_{i}^{(k)}$ pada bus pembangkit dengan persamaan (35)(36).

4. Hitung elemen-elemen matrik Jacobian $J_{1}, J_{2}, J_{3}$ dan $J_{4}$ dengan persamaan (39) sampai persamaan (46).

5. Hitung nilai $\Delta \delta_{i}^{(k)}$ dan $\Delta\left|V_{i}^{(k)}\right|$ menggunakan persamaan (38).

6. Hitung nilai-nilai baru dari sudut fasa dan tegangan, $\delta_{i}^{(k+1)}$ dan $\left|V_{i}^{(k+1)}\right|$ dengan persamaan (49) dan (50).

7. Proses ini berlangsung sampai $:\left|V_{i}^{(k+1)}-V_{i}^{(k)}\right| \leq \epsilon$

\section{Metode Penelitian}

Penelitian ini akan dilaksanakan dalam beberapa tahapan seperti berikut :

1. Pemodelan Sistem sistem tenaga listrik menggunakan Software ETAP 4.0

2. Menginputkan data, yaitu : data pembangkit, Trafo, Saluran transmisi, dan beban yang diperoleh dari UPB PT.PLN

3. Menghitung aliran daya dengan metode Newton-Raphson

4. Mengevaluasi aliran daya dan tegangan bus di setiap bus yang ada dalam sistem.

Berikut adalah diagram alir (flowchart) perhitungan aliran daya menggunakan metode Newton-Raphson. 


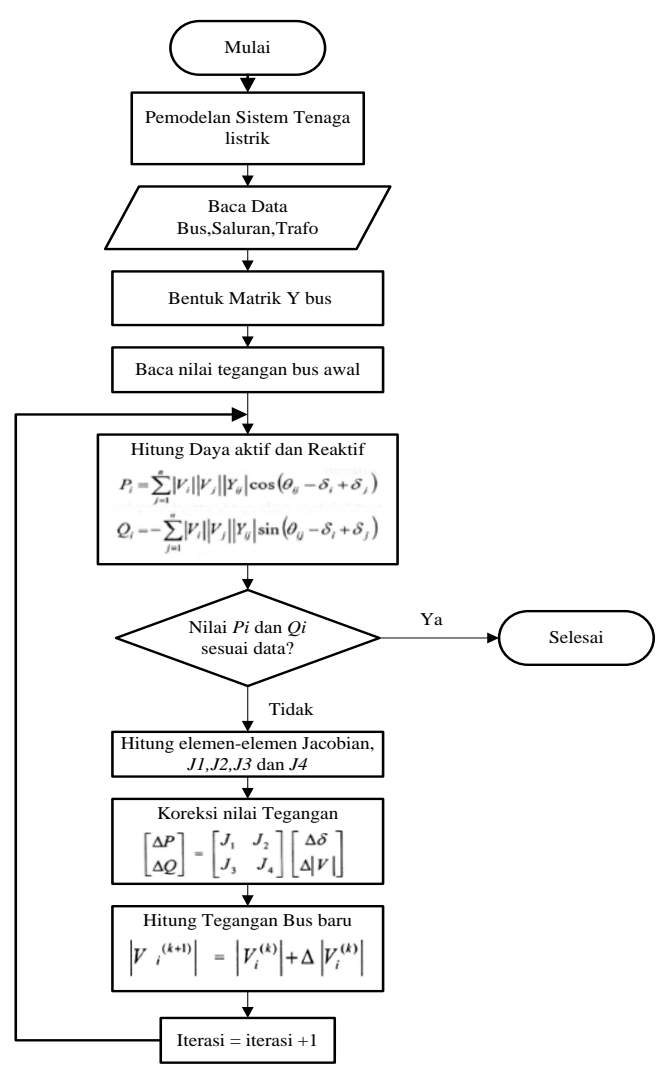

Gambar 3.1. Diagram alir perhitungan aliran daya menggunakan metode Newton-Raphson

\section{Hasil Penelitian}

Hasil simulasi aliran daya menggunakan software ETAP 4.0 dapat dilihat bahwa :

Aliran daya aktif terbesar mengalir dari bus Tebing Tinggi ke bus Sei Rotan sebesar 133,04 MW dan daya reaktif sebesar 66,8 MVAR mengalir dari bus Belawan ke bus Sei Rotan (Tabel 4.1)

\begin{tabular}{|c|c|r|r|r|r|}
\hline \multirow{4}{*}{$\begin{array}{c}\text { Dari } \\
\text { Bus }\end{array}$} & \multirow{2}{*}{$\begin{array}{c}\text { Ke } \\
\text { Bus }\end{array}$} & $\begin{array}{c}|c| \\
\text { Aliran } \\
\text { Daya }\end{array}$ & \multirow{2}{*}{$\begin{array}{c}\text { Arus } \\
\text { Aktif } \\
\text { (MW) }\end{array}$} & $\begin{array}{c}\text { Daya } \\
\text { Reaktif } \\
\text { (MVAR) }\end{array}$ & $\begin{array}{c}\text { Faktor } \\
\text { (A) } \\
\text { Daya } \\
\text { (\%) }\end{array}$ \\
\hline \multirow{7}{*}{ Blwn } & Bnje & -23.53 & 24.05 & 129 & -69.9 \\
\hline & Lbhn & 13.60 & 8.64 & 62 & 84.4 \\
\hline & P.Pasir & -35.74 & 20.41 & 158 & -86.8 \\
\hline & SRtan & -104.35 & $\mathbf{6 6 . 8 0}$ & 476 & -84.2 \\
\hline & Prbngan & 71.42 & -28.38 & 296 & -92.9 \\
\hline
\end{tabular}

\begin{tabular}{|c|c|r|r|r|r|}
\hline \multirow{7}{*}{$\begin{array}{c}\text { Tebing } \\
\text { Tinggi }\end{array}$} & & -23.51 & 8.82 & 96 & -93.6 \\
\cline { 2 - 6 } & K.Pnjng & -50.87 & 18.70 & 208 & -93.9 \\
\cline { 2 - 6 } & SRtan & $\mathbf{1 3 3 . 0 4}$ & -62.91 & 567 & -90.4 \\
\cline { 2 - 6 } & P.Sntar & -57.59 & 10.66 & 225 & -98.3 \\
\cline { 2 - 6 } & Bus46 & 35.98 & 23.75 & 166 & 83.5 \\
\hline
\end{tabular}

Tabel 4.1 Aliran Daya Aktif dan Reaktif

Sedangkan penurunan tegangan (voltage drop) terbesar terjadi pada bus Aek Knopan yaitu sebesar 3,035 \% $(0,61 \mathrm{KV})$ dari tegangan normal $20 \mathrm{KV}$ menjadi 19,393 $\mathrm{KV}$, untuk sistem $150 \mathrm{KV}$ terjadi pada bus yang sama yaitu sebesar $0,151 \%(0,23 \mathrm{KV})$ sehingga tegangan menjadi $149,773 \mathrm{KV}$. (Tabel 4.2).

\begin{tabular}{|c|c|c|c|c|c|}
\hline \multirow{2}{*}{$\begin{array}{c}\text { Nama } \\
\text { Bus }\end{array}$} & \multirow{2}{*}{$\begin{array}{c}\text { Teg. } \\
\text { Bus } \\
\text { (KV) }\end{array}$} & \multicolumn{2}{|c|}{$\begin{array}{c}\text { Hasil } \\
\text { Perhitungan }\end{array}$} & \multirow{2}{*}{$\begin{array}{l}\text { Sudut } \\
\text { Beban }\end{array}$} & \multirow{2}{*}{$\begin{array}{l}\text { Vd } \\
(\%)\end{array}$} \\
\hline & & $\begin{array}{l}\text { Teg. } \\
\text { (KV) }\end{array}$ & $\begin{array}{l}\text { Teg. } \\
(\%)\end{array}$ & & \\
\hline $\begin{array}{l}\text { Aek } \\
\text { Knopan }\end{array}$ & 150 & 149,773 & 99,85 & $\mathbf{0 , 3}$ & 0,151 \\
\hline Bus 55 & 20 & 19,393 & 96,97 & -2 & 3,035 \\
\hline
\end{tabular}

Tabel 4.2 Tegangan dan Sudut beban saat keadaan normal

\section{Kesimpulan}

Beberapa kesimpulan yang dapat diambil dari simulasi aliran daya pada Sistem Tenaga Listrik di Sumatera Utara dan Aceh menggunakan perangkat lunak ETAP 4.0 sebagai berikut :

1. Daya Aktif terbesar mengalir dari bus Tebing Tinggi ke bus Sei Rotan sebesar 133,04 MW.

2. Daya Reaktif terbesar mengalir dari bus Belawan ke bus Sei Rotan sebesar 66,80 MVAR.

3. Penurunan tegangan (Voltage Drop) terbesar terjadi pada bus Aek Knopan yaitu sebesar 3,035\% dari tegangan normal $20 \mathrm{KV}(19,393 \mathrm{KV})$ untuk sistem $20 \mathrm{KV}$. 
4. Sementara untuk sistem $150 \mathrm{KV}$, penurunan tegangan (Voltage Drop) sebesar $0,151 \% \quad(149,773 \mathrm{KV})$ terjadi pada bus yang sama.

\section{Saran}

1. Untuk mendapatkan aliran daya yang optimal maka hal yang perlu di perhatikan adalah profil tegangan setiap bus dalam sistem harus tetap berada dalam batas yang diizinkan yaitu dengan mengalokasikan sumber-sumber daya reaktif yang sesuai. Sumber-sumber daya reaktif misalnya : Generator dan transformator.

2. Hasil simulasi aliran daya ini dapat dikembangkan untuk simulasi dan analisis yang lain, seperti :

a. Analisa hubung singkat (Short Circuit Analysis)

b. Analisa Harmonisa (Harmonic Analysis)

c. Analisa Stabilitas Peralihan (Transient-Stability Analysis)

d. Analisa Aliran Daya Optimal (Optimal Load Flow Analysis)

e. dan lain-lain

\section{Ucapan Terima Kasih}

Ucapan terima kasih kami sampaikan kepada pihak pengelola PHKI Batch IV yang telah memberikan dukungan dalam bentuk dana hibah, sehingga terlaksananya penelitian ini.

\section{Daftar Pustaka}

[1] Amin,N., 2011, Perbandingan metode Gauss-Seidel dan metode NewtonRaphson dalam solusi Aliran Daya, Jurnal SMARTek, Vol.9, No.3, hal. 212-222, Univ. Tadulako,Palu

[2] Amirullah,2009, Analisis kontingensi tegangan bus dan daya saluran pada sistem Jamali $500 \mathrm{KV}$ menggunakan metode Performansi Indeks, Prosiding SENTIA, Malang
[3] Cekmas,C, 2004, Sistem Tenaga Listrik, contoh soal dan penyelesaiannya menggunakan MATLAB, Penerbit Andi Yogyakarta

[5] Hartoyo, 2006, Perbaikan keandalan (N-1) Sistem tenaga Listrik PLN Jawa Tengah dan DIY, FT Universitas Negeri Yogyakarta, Yogyakarta

[6] Hosea,E dan Tanoto,Y., 2004, Perbandingan Analisa aliran daya dengan menggunakan metode Algoritma Genetik dan Metode Newton-Raphson, Jurnal Teknik Elektro, Vol.4,No.2, hal. 63-69

[7] Saadat,H.,1999, Power System Analysis, WCB McGraw-Hill Series In Electrical and Computer Engineering,Milwaukee School of Engineering, New-york

[8] Stagg, G.W. and El-Abiad, A.H., 1968, Computer Methods in Power System Analysis, Mc.Graw-Hill, New-york

[9] Stevenson,Jr.,W.D., 1996, Analisis sistem tenaga listrik, edisi ke-4. Terjemahan Kamal Idris, Penerbit Erlangga, Jakarta

[10] Syamsurijal, 2008, Aplikasi Power World Simulator pada Analisis kontingensi Sistem Tenaga Listrik, Media Elektrik, Vol.3,No.2. 